\title{
Muslim Women of West Bengal: An Enquiry into their Minority Status
}

\author{
Md. Intekhab Hossain ${ }^{1}$ \\ ${ }^{1}$ Lecturer, Department of Sociology, Aliah University, India
}

\begin{abstract}
Sociological and social anthropological research studies on the Muslim society in India with particular reference to the women of West Bengal are negligible causing immense loophole in our insight and understanding the Muslim society from empirical point of view. Because of this fact, we hardly know about their society, economy, social structure, social organization, culture, social problems, social change and developmental processes, gender studies of the Muslim society.

The present paper is a modest attempt to examine the socio-economic situation of the largest religious minority population compared to other religious minorities of the state generally, and the status of Muslim women of West Bengal in particular. An attempt has also been made to highlight the socio-economic backwardness prevailed among this group of people from historico-religious perspective and to find out the factors contributing as a bottleneck in their development and social change.
\end{abstract}

Keywords: Muslim Women, Minority, Situation, Backwardness, Development.

'The claim of a country civilization depends upon the treatment to the minorities'Mahatma Gandhi.

\section{INTRODUCTION}

The Muslims of West Bengal hitherto remains unexplored for this we have very insufficient and little awareness about their society in general and the situation of Muslim women in particular in comparison to the women in other religious groups due to the social scientists, scholars, academicians, planners and policy makers, researchers and social activists etc. who have not paid as their much attention to the Muslims. It is estimated that one-fourth of the total population of West Bengal are Muslims by religion and are the biggest and principal minority of the state comprising about ninety six percent to the total minority population of the state and about twenty five percent population of this state are belongs to the Muslim community, according to 2001 census report of India, inhabiting in all the districts of West Bengal in various quantity. There are twelve such districts where the Muslims represent about twenty five percent to the respective district's total population and at the same time as in the districts like North Dinajpur, Malda and Murshidabad their population represents more than fifty percent to the total population of the respective districts.

Muslims have been found most educationally backward religious minority community at national level and for which the Government of India acknowledged them 'National Educationally Backward Minority' in 1993 nevertheless the destiny of the Muslims of Indian has not changed in the last sixty two years of independence when they are again found most underprivileged section of the country by the Sachar Committee Report of 2006.

Despite the fact that overall progress of any nation or state is not possible without considering its women irrespective of their caste, color and creed as they represent about half of the population. The Muslim women of West Bengal are lagged behind the mainstream on all human development indicators since independence due to various external and internal factors. They have not received ample attention of the academicians, Government and also social workers although there is an acute need to undertake researchers in order to find out the factors contributing as a bottlenecks in their development and social change and their multifarious problems specific to Muslim women. They are still remained socially, economically and educationally towards the back when change is the assortment of today. Empowerment of women implies their better position in socio-political and economic spheres. Muslim women's empowerment is crucial as they continue to be victimized by traditional social structure, social systems and social institutions of the community when modernization of women in India is a potential medium. The educational backwardness of majority of the Muslim women is one of the crucial 
factors for their way behind, employment and economic empowerment is also indispensable for raising status in social hierarchy and social change. Therefore, lack of education, economic dependency, poverty and ignorance of their rights has made them further vulnerable to exploitation.

\section{MINORITIES: CONCEPTS AND THE CONSTITUTION}

Since the 1930s this term has been applied to social groups that are oppressed or stigmatized on the basis of racial, ethnic, biological, or other characteristics. Louis Writh, for example, defines a minority group as 'a group of people who, because of their physical or cultural characteristics, are singled out from the others in the society in which they live for differential and unequal treatment and who therefore regard themselves as objects of collective discrimination'. However, seen in these terms, a minority group could in fact constitute a numerical; majority in any society-for example Blacks in South Africa. It might be more useful, therefore, to distinguish between groups which are actually a minority in numbers and those which are marginal in terms their access to power (DOS, 2009: 476). ${ }^{1}$ A minority is a group of people subjected to prejudice and discrimination in a given society. Sociologically speaking, minority groups are not necessarily numerically small groups; they are simply victims of differential and unequal treatment. In the United States, blacks are a minority, numerically and sociologically. But in South Africa under the apartheid system, blacks were the majority group, a predominant majority that was discriminated against by a small group of whites who had the power. In India, the government makes a distinction between 'minorities' and 'weaker sections'. Muslims, Christians, Sikhs, Buddhists, Zoroastrians, and jains, as well as the handicapped and the elderly are treated as minorities. Note that these are all numerically smaller groups. But Dalits, tribals, and backward classes are treated as 'weaker sections'. Women are also categorized as weaker sections whether or not they are numerically small. Therefore, it appears that 'weaker sections' actually mean 'minorities' or groups who suffer discrimination and unequal treatment (Abraham, 2009:135-136). ${ }^{2}$ Minority Right has been a problematic issue for international law to handle. Although international law primarily deals through the medium of states and minorities generally have no locus standing, the treatment which minorities receive from their states has increasingly become a matter of international concern. International law, however, has historically found it difficult to deal with the problems around minorities. Like the poor, the week and the inarticulate, minorities have historically fallen victim to persecution and genocide. Even in the contemporary period of relative tolerance and rationality, minorities are often subjected to persecution, discrimination and genocide. The stance of international law remains tentative and extremely cautious, for minorities pose questions of a serious nature; they exit in myriad forms, with their own social, political, cultural and religious particularities (Rehman and Hoffler, 2010: 282-283). ${ }^{3}$ Mahmood (2001:06) ${ }^{4}$ has pointed out, from the Constitution of India, 1950, e.g., Articles 30, 350-A and 350-B, that in India, the National Constitution of 1950 or any other Constitutional document does not define the word 'Minority'. The Constitution only refers to Minorities and speaks of those "based on religion or language". In the constitution of India, the Preamble (as amended in 1976) declares the State to be "Secular", and this is of special relevance for the Religious Minorities. Equally relevant for them, especially, is the prefatory declaration of the Constitution in its Preamble that all citizens of India are to be secured "liberty of thought, expression, belief, faith and worship and "equality of status and opportunity." By constitution India is "secular", "democratic" and "republic". It gives recognition to all religions professed by the citizens of India and also gives recognition to group identities as such. The constitution of India guarantees to all citizens of India the social, economic and political justice; liberty of thought, expression, belief, faith and worship; equality of status and opportunity; and seeks to promote fraternity among Indians in order to assure the dignity of individuals and the unity of the nation.

Part III of the constitution deals with the Fundamental Rights and gives assurance to all citizens of India that no discrimination will be permitted on the grounds of religion, race, caste, sex or place of birth (Article-15). This acquires significance in the case of Muslims on the ground of their position as a religious or cultural minority in India. The constitution also assures equality of opportunity to all in the matters of employment under government (Article-16). It gives freedom of speech, expression, residence, acquisition and disposal of property, practice of profession, free association and free movement (Article-19), gives the right of freedom of religion (Article-25), protects the cultural and educational rights of the minorities (Article-29). All these provisions also acquire significance when applied to the Muslim community, who constitutes one of the important cultural minorities of the country. 
Every Muslim citizen of India is individually a member of a distinct religious community, which together with other religious communities constitute the Indian nation. Therefore every Muslim citizen of this country individually and Muslims as a whole collectively are the part of Indian nation (Mondal, 1992: 157). ${ }^{5}$

\section{SITUATION OF MUSLIM WOMEN OF WEST BENGAL}

Muslims are mostly self-employed and their share in regular paid jobs is low. The Hindu population is relatively better employed in regular salary-paying jobs in urban areas. The work participation of Muslim females is extremely low. The landholding is better among Hindus than Muslims, and Muslims work on non-agricultural occupation in substantial proportions in rural part of India. Muslims, are, by far, the least educated when compared with Hindus and Christian populations in India (Shariff, 2003: 92). ${ }^{6}$ W. W. Hunter states that, "....earlier it was impossible for a well born Musalman to become poor; at present it is almost impossible for him to continue rich" (Hunter, 1969:158). ${ }^{7}$ Any assessment of the socio-economic conditions of Muslims in India needs to recognize that, like other minorities, issued faced by Muslims are multifaceted as they simultaneously face problems relating to security, identity, and equity. And the interplay of these dimensions is at the core of the socio-economic and political processes that the community is exposed to on a daily basis. An empirical exploration of these multidimensional issues is typically hampered by the non-availability of relevant 'hard and unbiased' data. Such data constraints are typically more severe for security and identity-related concerns (Basant and Shariff, 2010: 02). ${ }^{8}$

\section{Figure: 1. Percentage Distribution of Muslim population in West Bengal Districts}

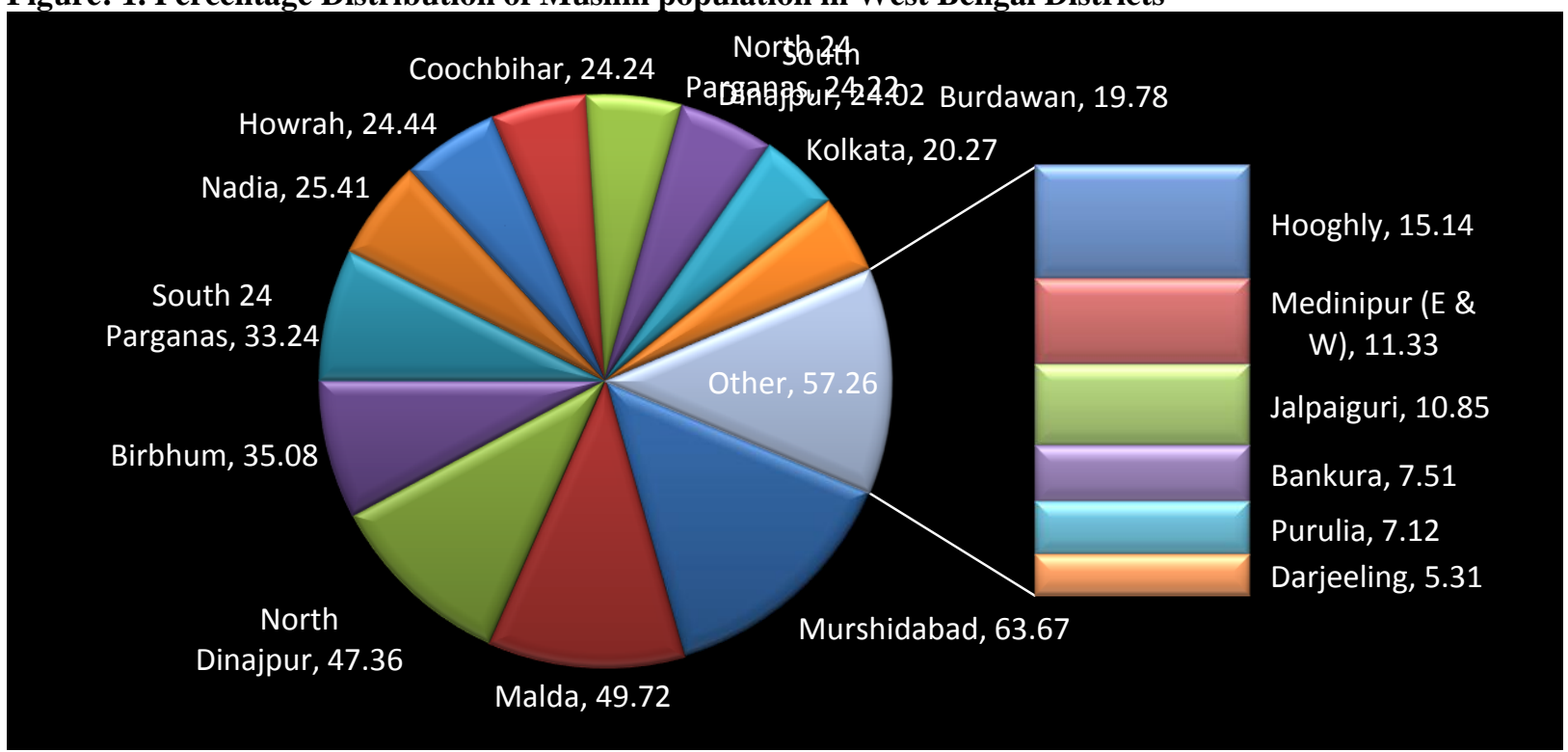

Source: Govt. of India, Census Report, 2001

Figure: 2. Sex Ratio among various Religious Communities of West Bengal

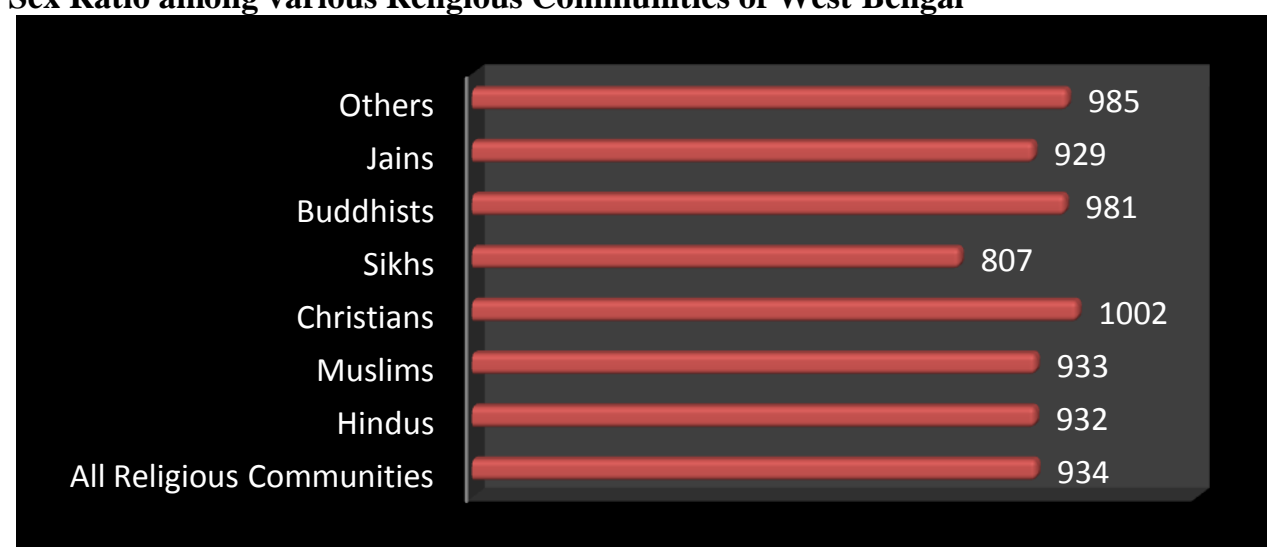

Source: Govt. of India, Census Report, 2001

Figure: 3. District Wise Rate of Literacy on the basis of Sex between General and Muslim Religious Communities of West Bengal (In per cent) 


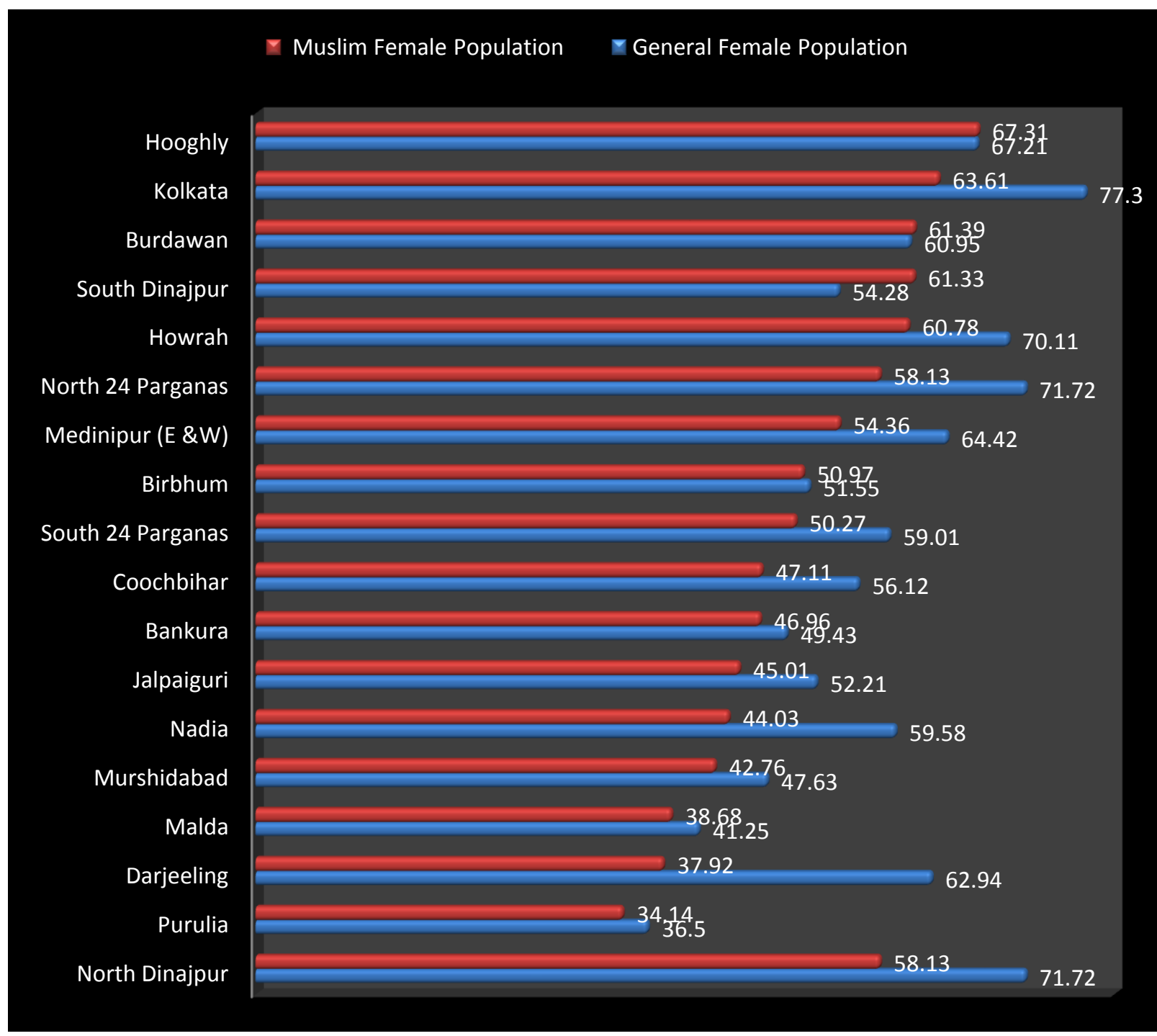

Source: Govt. of India, Census Report, 2001

The education commission, Ministry of Education, Government of India, 1966, stated that it is the responsibility of the educational system to bring different social classes and groups together to promote the emergence of an egalitarian and integrated society. But unfortunately the educational development is very poor in India. Various efforts have been taken in the post independent period to spread education among the masses. But result is not very satisfactory, especially in the context of scheduled castes, scheduled tribes, minorities and other backward communities or weaker sections (Mondal, 1997:19). ${ }^{9}$ Enrolment rates at the primary level have risen considerably, but many of the students who enroll drop out and only a very small number manage to get beyond the primary stage. Gender inequality in education is one important aspect of educational disparity. Inequality and differences between communities is another critical aspect of this brother phenomenon of disparity in India. Though the census reports remain silent on the educational status of Muslims, it is well known that the literacy and educational levels of Muslims is below the national average.

The educational backwardness of Muslim women is a matter of particular concern, especially the high drop-out rate, resulting in subsequently fewer proportions of them managing to complete high school, and even less availing of higher education. Not surprisingly, Muslim women account for the lowest levels of educational attainment (Hasan and Menon, 2004:47). ${ }^{10}$ There is also a common belief that Muslim parent feel that education is not important for girls and that it may instill a wrong set of values. Even if girls are enrolled, they are withdrawn at an early age to marry them off. This leads to a higher drop-out rate among Muslim girls. Our interactions indicate that the problem may lie in non-availability of schools within easy reach for girls at lower levels of education, absence of girl's hostels, absence of female teachers and availability of scholarships as they move up the education ladder (GOI, 2006:85). ${ }^{11}$ Muslims in India are facing two major problems-education and 
employment which are essential for the socio-economic development of human beings. It is evident that Muslims in India as well as Muslims in West Bengal are lagging behind in terms of quantitative and qualitative education.

It is evident that the condition of Muslims in West Bengal in the field of education is very poor, even poorer than SCs/STs. Again, women's education among Muslims in the state is lower than men. It is seen that the educational status of Muslims in West Bengal, like other parts of the country, is also depressing. Among various reasons, the major reasons for educational backwardness among the Muslims are poor economic condition, limited number of government and government aided schools in Muslim areas and lack of job opportunities of the educated people in the community. Perhaps Muslim women are lagging behind in education because of socio-cultural pattern of the family and the society, the negative attitude towards girls' education and are lack of infrastructural facilities for education in Muslim concentrate4d areas. Muslims have limited access to far off school. Need of the hour is to provide job oriented education and also to set up sufficient number of technical schools for male and female separately in the Muslim concentrated areas (Rahaman and Bhuimali, 2011: 84 and 91). ${ }^{12}$

Figure: 4. Work Participant Rate on the basis of Sex among various Religious Communities of West Bengal (In Per cent)



Source: Govt. of India, Census Report, 2001

Figure: 5. District Wise Work Participant Rate among the Muslim Females of West Bengal (In per cent)

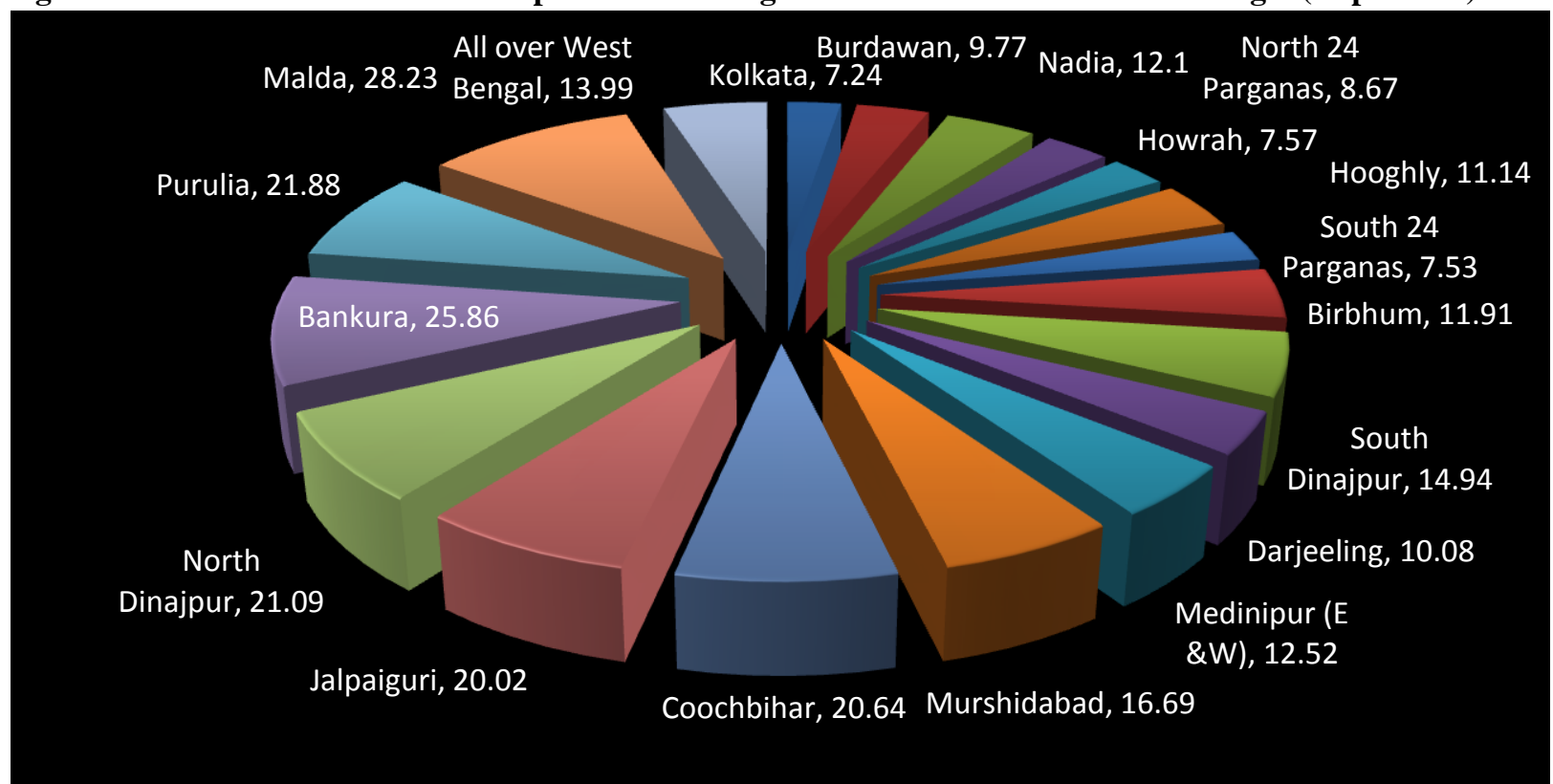

Source: Govt. of India, Census Report, 2001 
Muslim Women of West Bengal: An Enquiry Into Their Minority Status

Table: 1. District Wise Female Work Participant Rate in Various Occupations among the Muslims of West Bengal (In per cent)

\begin{tabular}{|c|c|c|c|c|c|}
\hline Sl. No. & Districts & Cultivators & $\begin{array}{c}\text { Agricultural } \\
\text { Laborers }\end{array}$ & $\begin{array}{l}\text { Household } \\
\text { Industry }\end{array}$ & Other Workers \\
\hline 1. & Kolkata & 1.76 & 0.67 & 13.04 & 84.53 \\
\hline 2. & Burdawan & 11.39 & 16.83 & 27.53 & 44.25 \\
\hline 3. & Nadia & 18.91 & 7.95 & 24.57 & 48.57 \\
\hline 4. & North 24 Parganas & 7.50 & 15.30 & 23.28 & 53.92 \\
\hline 5. & Howrah & 2.50 & 5.24 & 52.01 & 40.25 \\
\hline 6. & Hooghly & 12.83 & 14.48 & 29.30 & 43.39 \\
\hline 7. & South 24 Parganas & 10.27 & 29.51 & 21.22 & 39.00 \\
\hline 8. & Birbhum & 9.76 & 12.90 & 46.25 & 31.10 \\
\hline 9. & South Dinajpur & 23.05 & 31.41 & 6.66 & 38.89 \\
\hline 10. & Darjeeling & 7.25 & 28.49 & 2.75 & 61.51 \\
\hline 11. & $\begin{array}{l}\text { Medinipur (East } \\
\& W e s t)\end{array}$ & 12.65 & 27.19 & 31.12 & 29.04 \\
\hline 12. & Murshidabad & 3.61 & 4.14 & 74.13 & 18.11 \\
\hline 13. & Coochbihar & 30.77 & 53.32 & 3.29 & 12.61 \\
\hline 14. & Jalpaiguri & 20.34 & 47.55 & 1.99 & 30.12 \\
\hline 15. & North Dinajpur & 25.47 & 45.33 & 11.81 & 17.40 \\
\hline 16. & Bankura & 17.58 & 19.52 & 39.40 & 23.50 \\
\hline 17. & Purulia & 20.07 & 55.50 & 12.46 & 11.97 \\
\hline 18. & Malda & 4.88 & 14.16 & 74.13 & 18.11 \\
\hline \multicolumn{2}{|c|}{ All over West Bengal } & 11.01 & 19.21 & 38.95 & 30.84 \\
\hline
\end{tabular}

Source: Govt. of India, Census Report, 2001

Predominantly rural, the Muslim population in the state is engaged in agricultural pursuits, a very large number of them work as agricultural labour and many others suffer from unemployment and under-employment. Facilities for education are awfully inadequate and to the extent they are available, they are beyond easy reach of their overwhelmingly large number, because of the cost involved.

Impelled to resort to self employment for their survival a substantial number specializes in a few crafts like carpentry, needle and zari works, tailoring, embroidery, paper crafts and the occupation of gold smith etc. and such odd jobs like rickshaw pulling, which draw them to cities including Delhi and Bombay. Kolkata provides very limited scope for their presence in the city is not quite significant. Day labourers, including women from poverty stricken families from suburban areas, arriving to the city every morning, largely through local trains quite often get grossly exploited. The sad tales of their sufferings deserve serious attention.

The presence of Muslims from rural areas of West Bengal from districts, in the city is so negligible that a few educated Muslim youth, arriving to the city in search of employment do not find accommodation in suitable areas, and under situational pressure have to change their name for obtaining place to live in non-Muslim areas. These and similar other social facts go to explain the overall prevailing social situation (Siddiqui, 2011:213214) ${ }^{13}$ The societal pluralism of India, as fortified by the unique Constitutional concept of secularism, raises the need for the protection and development of all sorts of weaker sections of the Indian citizenry-whether this "weakness" is based on numbers or on the social, economic or educational status of any particular group. The Constitution, therefore, speaks of Religious and Linguistic Minorities, Scheduled Castes, Scheduled Tribes and Backward Classes and makes- or leaves room for making-for them special provisions of various natures and varying import (Mahmood, 2001:13-14).${ }^{14}$ On the completion of five decades of independence, women in Muslim communities face considerable challenges as citizens of India and as members of India's largest minority. Their poor socio-economic status reflects a lack of social opportunity which, though not a feature exclusive to Muslim women, is exacerbated by their marginal status within an overall context of social disadvantage for most Indian women.

According to government reports, Muslim women are among the poorest, educationally disenfranchised, economically vulnerable, politically marginalized group in the country.

A lack of information on Muslim women contributes to the reinforcement of cultural stereotypes, serving to obfuscate their life experiences and struggles. Consequently, the notion that Muslim women's status in India is 
attributable to certain intrinsic, immutable 'Islamic' features or that their social status derives solely from Muslim laws is widely prevalent.

In a context where the Shari'a is used to justify women's subordination, it is imperative for Muslim women in India to enter the discourse on the Shari'a with reference to personal law, and challenge their historic marginalization from religious knowledge.

The lack of social opportunities for Muslim women is a crucial issue needing urgent action. An improvement in literacy rates would directly influence Muslim women's socio-economic and political status as citizens of India.

The acknowledgement of the universality of women's rights by the international community is relevant to the debate on Islam and women's rights, particularly with reference to women's rights in the family (Kazi, 1999:31). ${ }^{15}$ Observing a general lack of knowledge about the meaning and implications of being a minority the author is critical of the people who discourage revealing the facts of extremely bad socio-economic condition of the Muslims for fear of making them unnerved. Revealing truth is necessary for creating awareness leading to the solution of the problem.

Quoting reports of the national Family Health Survey it is shown that Muslim Women are seven times behind Hindu women in high school education and in post-high school they are nine times behind them.

Muslims in rural Bengal bare predominantly engaged in agriculture, a very large number of them are agricultural labour. They also specialize in several handicrafts. Predominantly much smaller number of Muslims from districts has come to live and work in this difficulty they have to change their name to conceal; their identity.

Over 75\% of Muslims in Calcutta live in bustees, large areas of their abode have been acquired by the authorities and t5hey have been seldom resettled in the area developed. They are the victims of the wrong notion of being a floating population. Nearly $80 \%$ are either born in the same bustee, or in Calcutta or in West Bengal. 4 percent of the total numbers of children are enrolled in recognized schools and a total of $9 \%$ attend same sort of school recognized or unrecognized and $91 \%$ do not have any school to attend. Those enrolled hardly complete school education and $90 \%$ of the enrolled get dropped out. Child labour is rampant.

Occupational structure of the Muslims in Calcutta differs sharply from that of the Hindus. Their bustees are the hub of a number of handicrafts besides providing them space to live. Action programme to improve the overall condition has to keep in mind both economy and education because of their interdependence (Siddiqui, 2011: $210-211){ }^{16}$

\section{CONCLUDING OBSERVATIONS AND REMARKS}

Despite the fact that a good number of the studies mostly advocates towards the Islamic theology, ideology, historical perspectives, religious reformatory movements, laws, and the like, social scientists like sociologists and social anthropologists, academicians, researchers, scholars, social activists, planners and policy makers etc. have not paid much attention to the Muslims in general and the women of their society in particular as it deserves. while, in recent past very insignificant amount of studies were in print but those are too tiny to fill the gap of our insight and understanding about the people under study and because of which we hardly be acquainted with the dynamics of Muslim society, social structure, and social organization, social problems, social change, culture, subsistence economy, process of development and last but not the least on the subject of gender studies of the Muslims societies.

By reviewing the overall circumstances of the Muslim women of West Bengal it has been observed that the situations are very pitiable almost in every facet of development. In respect of educational attainment, participation in gainful jobs, economic and political empowerment the women in Muslim society are most marginalized, underprivileged, secluded and are in a state of hardship and lagged behind the mainstream which retarded them in normal progress in the field of education, economy, politics, knowledge and culture. It is a visible fact that the educational status of the Muslims with particular reference to the women is very low, inadequate and negligible due to complex panorama of educational problems among the Muslim women of West Bengal where historical, situational, educational and socio-cultural variables are together playing the key roles to perpetuate the situation in the contemporary time when modernization is the order of the day. Moreover the Ranganath Misra Commission Findings and the Sachar Committee Report in addition have revealed the fact 
that Muslims are socio-economically, educationally, politically and culturally underprivileged and way behind the mainstream Indian society.

The multifaceted strange troubles faced by them are coupled with anxieties pertaining to security question, identity perception, discrimination and justice. The economic backwardness of the Muslim women is a recurring and enduring process as it is leading to social and educational backwardness and in turn is resulting in their economic backwardness further. Again the consequential result of educational backwardness creates a sort of social and cultural setting among them which perpetuates the elements of orthodoxy and traditionboundness among the Muslims of West Bengal. One thing is conspicuous that Muslims as a whole have been suffering from the apparent prejudice and deprivation in almost every section of the society. These people are at the lowest platform of the society and have need of affirmative action.

The prime thing which is necessary for socio-economic development of the women in Muslim society is their awareness, spontaneous motivation and their participation in different developmental programmes for their progress in the given society. Like other backward communities in India, the backwardness of the Muslims women in their society is a national crisis and should be documented as a setback of the entire territory so that the nation as a whole act together to get rid of this menace.

Again last but not the least despite the fact that the plight of Muslim women of West Bengal is much worse than other social groups, in recent times due to impact of a mixture of factors which are well thought-out to be the paramount for the progress of any social group irrespective their color, creed, sex, race etc. such as modernization, urbanization, westernization, globalization, changes in socio-economic facet, democracy, opening out in the means of communication, proper allocation and utilization of Government infrastructure, mass media, spread of education, lawful enactment regarding the marginal section of the society like Muslim, their society is gradually undergoing changes in advancing towards masculinity and femininity coming out from their frustration, low level of aspiration, fear psychosis and traditionboundness nature, inferiority and minority complex. All these characteristics which had kept these people immobilized and retarded from the normal progress in social ladder for long time starving from social change and upward vertical and horizontal mobility are now giving the way to improvement and empowerment of both Muslim men and women of West Bengal.

\section{REFERENCES}

[1] J. Scott and G. Marshall (Eds.), Oxford Dictionary of Sociology (New York: Oxford University Press Inc., 2009).

[2] M. F. Abraham, Contemporary Sociology: An Introduction to Concepts and Theories (New Delhi: Oxford University Press, 2009).

[3] J. Rehman and H. Hoffler, Regional/International Frameworks of Minority Protection in Europe and South Asia in S. K. Das (Ed.), Minorities in South Asia and in Europe: A New Agenda, (KOLKATA: SAMYA, 2010) 278-310.

[4] T. Mahmood, Minorities Commission: Minor Role in Major Affairs (New Delhi: Pharos Media \& Publishing (P) Ltd., 2001).

[5] S. R. Mondal, Muslims in India: An Enquary into their Minority Status, Backwardness, Special Rights and Development Problems, J. Indian Anthrop. Soc. 27, 1992, 149-160.

[6] A. Shariff, National Sample Survey Organization (NSSO), $43^{\text {RD }}$ ROUND, 1987-88, quoted in Sebastian Vempeny, Minorities in Contemporary India (New Delhi: Kanishka, 2003) 92.

[7] W. W. Hunter, The Indian Musalmans $3^{\text {rd }}$ edition (Delhi: Indological Book House, 1969).

[8] R. Besant, and A. Shariff, The State of Muslims in India in R. Besant and A. Shariff (Eds.), Oxford Handbook of Muslims: Empirical and Policy Perspectives, (New Delhi: Oxford University Press, 2010) 1-23.

[9] S. R. Mondal, Educational Status of Muslims: Problems, Prospects and Priorities (New Delhi: Inter-India Publications, 1997).

[10] Z. Hasan and R. Menon, Unequal Citizens: A Study of Muslim Women in India (New Delhi: Oxford University Press, 2004).

[11] Government of India, "Social, Economic and Educational Status of the Muslim Community of India - A Report", Prime Minister's High Level Committee, Cabinet Secretariat, Chairperson- Justice Rajindar Sacher (New Delhi: Government of India, 2006) 1-425.

[12] M.T. Rahaman, and A. Bhuimali, Indian Muslims and their Economy (Delhi: Abhijit Publications, 2011).

[13] M. K. A. Siddiqui, Muslims in India: Issues and Challenges (A collection of articles), (Kolkata: Abadi Publication, 2011).

[14] T. Mahmood, Minorities Commission: Minor Role in Major Affairs (New Delhi: Pharos Media \& Publishing (P) Ltd., 2001).

[15] S. Kazi, Muslim Women in India, A Report (London, UK: Minority Rights Group International, 1991) 1-38.

[16] M. K. A. Siddiqui, Muslims in India: Issues and Challenges (A collection of articles), (Kolkata: Abadi Publication, 2011).

Notes: Notwithstanding the fact that the provisional data of the Census Report of 2011, Government of India has been recognized on 31 st March 2011, however to avail the religion wise data, it will take about two to three years to be made such data in public. For this reason the preceding discussion, wherever required, is based on the Census data of 2001, Government of India i.e. The Census Report of India (New Delhi: Government of India, 2001). 